\title{
Combretastatin A-1 phosphate, a microtubule inhibitor, acts on both hepatocellular carcinoma cells and tumor-associated macrophages by inhibiting the Wnt/ß-catenin pathway
}

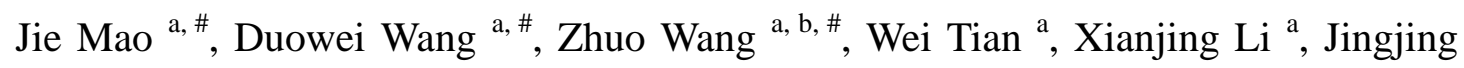
Duan ${ }^{\mathrm{a}}$, Yun Wang ${ }^{\mathrm{a}}$, Hongbao Yang ${ }^{\mathrm{a}}$, Linjun You ${ }^{\mathrm{a}}$, Yan Cheng ${ }^{\mathrm{a}}$, Jinsong Bian ${ }^{\mathrm{c}}$, Zhen Chen ${ }^{\mathrm{a}, *}$, Yong Yang ${ }^{\mathrm{a}, *}$

${ }^{\text {a }}$ State Key Laboratory of Natural Medicines, Jiangsu Key Laboratory of Drug Discovery for Metabolic Disease, Center for New Drug Safety Evaluation and Research, China Pharmaceutical University, Nanjing 211198, China

${ }^{\mathrm{b}}$ School of Pharmacy, Nanjing University of Chinese Medicine, Nanjing 210023, China

${ }^{c}$ Department of Pharmacology, Yong Loo Lin School of Medicine, National University of Singapore, 117597, Singapore.

${ }^{\#}$ These authors contributed equally to this work.

* Corresponding author: Yong Yang or Zhen Chen, China Pharmaceutical University, No 639, LongmianRd, Nanjing 211198, Jiangsu, China; Tel: (86)-25-86185622; Fax: (86)-25-86185622.Email: yy@cpu.edu.cn or cz@cpu.edu.cn.

Abbreviations: BMDMs, bone marrow-derived macrophages; BSA, bovine serum albumin; CA1, combretastatin A1; CA1P, combretastatin A-1 phosphate; CA4P, combretastatin A-4 phosphate; FBS, fetal bovine serum; GFP, green fluorescent protein; HCC, Hepatocellular carcinoma; IC50, half maximal inhibitory concentration; MMP, mitochondrial membrane potential; ROS, reactive oxygen species; TAM, tumor-associated macrophage; TME, tumor microenvironment; TUNEL, terminal deoxynucleotidyltransferase-mediate ddUTP nick end-labeling; WB, Western blot. 


\section{ABSTRACT}

Combretastatin A-1 phosphate (CA1P) is a microtubule polymerization inhibitor that binds to the colchicine-binding site of tubulin. We demonstrated that CA1P has outstanding anti-cancer activity against hepatocellular carcinoma (HCC) in vitro and in vivo. As determined by fluorescence staining and western blots (WBs), CA1P induced reactive oxygen species (ROS) accumulation and apoptosis in HepG2 cells with a down-regulation of Mcl-1. Additional studies indicated that CA1P induced microtubule depolymerization-mediated AKT inactivation, which resulted in GSK-3 $\beta$ activation, Wnt/ß-Catenin pathway inhibition, and Mcl-1 down-regulation. The induction of HepG2 cell apoptosis by CA1P was prevented by a GSK-3 $\beta$-specific inhibitor. Furthermore, immunohistochemistry studies on hepatocellular carcinoma mouse models showed that CA1P had activity against tumor-associated macrophages (TAMs). CA1P induced TAM apoptosis in vitro through the same mechanism observed with HepG2 cells, and it eliminated TAMs in the tumor microenvironment (TME) in vivo. In TME, the expression of TGF- $\beta$ and TNF- $\alpha$ was also altered. The adoptive transfer of macrophages partly rescued the growth of tumor inhibited by CA1P. These findings indicate that CA1P has great potential to impact both cancer cells and the microenvironment, and our results should accelerate the application of CA1P for HCC therapy in clinic.

Keywords: Combretastatin A-1 phosphate; hepatocellular carcinoma; Wnt/ $\beta$-catenin; tumor-associated macrophage; Tumor microenvironment

\section{Introduction}

HCC is one of the leading causes of cancer-related death $[1,2]$. Curative options for $\mathrm{HCC}$ are limited to tumor ablation, resection and liver transplantation-methods that are applicable to only a few patients. Systemic therapy with the small molecule inhibitor sorafenib remains the best option for advanced HCC patients; it confers modest prolongation of overall survival [1, 3, 4]. However, emerging clinical evidence as well as preclinical findings reveal that VEGF-targeted therapy with 
sunitinib or sorafenib increases the invasiveness and metastatic behavior of tumor cells [5-7]. Therefore, new strategies are needed for HCC therapy.

The pathogenesis of HCC involves a complex multistep process, and HCC displays extensive genetic heterogeneity. Thus, some investigations have focused on the identificantion of common signaling pathways that link HCC with diverse etiologies to better define molecular mechanisms $[8,9]$. The $\mathrm{Wnt} / \beta$-catenin signaling pathway plays a critical role in embryonic development and cell proliferation, survival, self-renewal, and regeneration $[10,11]$. Recent studies have highlighted that the constitutive activation of $\mathrm{Wnt} / \beta$-catenin pathway may be important to establish and maintain the hepatic malignant phenotype [12-14]. This deregulated Wnt/ $\beta$-catenin signaling cascade has been observed in $~ 95 \%$ of HCCs $[15,16]$. The abnormal cytoplasmic and/or nuclear accumulation of $\beta$-catenin has been demonstrated in 17-40\% of HCCs [17], and it is correlated with metastasis and poor prognosis [8, 18], indicating that the $\mathrm{Wnt} / \beta$-catenin pathway may be a potential diagnostic indicator and therapeutic target of HCC. Unfortunately, despite the strong evidence of $\mathrm{Wnt} / \beta$-catenin pathway participation in HCC genesis and development, it has been difficult to target pharmacologically so far; new drugs targeting this pathway are urgently needed.

Cancer cells and the surrounding stroma are closely related and interact constantly. Among the tumor stroma cells, the immune-edited tumor-associated immune cells vitally affect the growth and evolution of cancerous cells. Macrophages are some of the most abundant immune cells in liver tissue, and once HCC develops, they can be attracted to hypoxic areas along a trail of necrotic debris emanating from such areas and "educated" into TAMs, which facilitate tumor angiogenesis, promote extracellular matrix degradation and remodeling, enhance tumor cell motility, and even cause drug resistance [19-21]. The interaction between macrophages and tumor cells ultimately promotes the development of $\mathrm{HCC}$, and current therapeutic strategy must take it into account to achieve better curative effect. Wnt overexpression is observed in tumor stroma, and $\mathrm{Wnt} / \beta$-catenin signaling is also activatied in tumor-associated-immune cells such as TAMs and Tregs [22]. However, the effect of 
Wnt/ $\beta$-catenin signaling on to TAMs is unclear and needs to be explored.

Combretastatins are compounds originally isolated from Combretum caffrum that have potent microtubule inhibitory activity. Seventeen natural combretastatin analogs have been isolated from Combretum caffrum and characterized; among these, Combretastatin A-4 phosphate (CA4P) and CA1P have the highest antitumor activity [23]. Both CA4P and CA1P bind to the colchicine-binding site of $\beta$-tubulin, inhibiting microtubule polymerization thereby distrupting the tumor vessels. CA4P is a well-characterized vascular targeting agent (VTA) that is being evaluated in several clinical trials. CA1P shows a more potent inhibition of tumor blood vessels. CA1P induces the shutdown of tumor blood vessels in a dose-dependent manner with a median effective dose of $3 \mathrm{mg} / \mathrm{kg}$, which is significantly less than the $43 \mathrm{mg} / \mathrm{kg}$ effective dose of CA4P, in a mouse model; tumor regression was also more obvious with CA1P [24]. Aside from functioning as a VTA, the mechanisms involved in the effects of CA1P on tumor cells and the TME are unclear.

A recent study showed that microtubule dynamics can regulate AKT signaling via dynactin p150, which promotes of GSK-3 $\beta$ phosphorylation on Ser9 [25], which may be involved in the $\mathrm{Wnt} / \beta$-catenin pathway. However, little attention has been given to the effect of VTAs on the Wnt/ $\beta$-catenin pathway, which may be an undiscovered mechanism by which CA1P acts against solid cancer, especially HCC.

The present study was designed to elucidate the effects of CA1P for HCC therapy in vitro and in vivo. Moreover, the molecular mechanism of CA1P on both cancer cells and microenvironment was explored.

\section{Materials and Methods}

\subsection{Cell culture}

Human hepatocellular carcinoma SMMC-7721, Bel-7402, HepG2, LM-3, and Huh7 cells, gastric carcinoma BGC-803 cells, breast carcinoma MDA-MB-435, MDA-MB-231, and MCF-7 cells, lung carcinoma A375, A549, and NCI-1975 cells, colorectal carcinoma HT-29 and CT-26 cells, mouse hepatocellular carcinoma Hepa1-6 cells, and mouse macrophage cell RAW 264.7 cells were purchased from the 
Shanghai Cell Collection (Chinese Academy of Sciences, Shanghai, China) and LM-3-green fluorescent protein (GFP) cells was purchased from Nanjing Gulou Hospital (Nanjing, China). Cells were cultured in Roswell Park Memorial Institute (RPMI) 1640 medium, Dulbecco's modified Eagle's medium or L-15 medium (GIBCO, Grand island, NY, USA) as recommended by the American Type Culture Collection (Manassas, VA, USA), and supplied with 10\% (vol/vol) heat-inactivated fetal bovine serum (FBS, GIBCO/Invitrogen, Carlsbad, CA, USA), $100 \mathrm{U} / \mathrm{ml}$ penicillin and $100 \mu \mathrm{g} / \mathrm{ml}$ streptomycin (GIBCO/Invitrogen, Carlsbad, CA, USA) at $37^{\circ} \mathrm{C}$ in a humidified $5 \% \mathrm{CO}_{2}$ incubator.

\subsection{Antibodies and chemicals}

CA1P, CA4P (Nanjing Chengong Ltd., Nanjing, China), sorafenib (Bayer, Shanghai, China), and paclitaxel (Peking Huatai pharmaceutical Ltd., Peking, China) were used as test and positive drugs, and CHIR-99021 (Selleck Chemicals, TX, USA) was used as a GSK-3 $\beta$ inhibitor. Polyclonal antibodies against Mcl-1, Bcl-2 and AKT were purchased from Abcam (Cambridge, UK). Polyclonal antibodies against GSK, $\beta$-catenin, c-myc, and PARP were purchased from Wanlei life sciences (Shenyang, China). Phospho-specific monoclonal antibodies against Gsk-3 $\beta$ (Ser 9) and AKT (Ser 473) were purchased from Cell Signaling Technology (USA). Monoclonal antibodies against $\alpha$-tubulin were purchased from Sigma Chemical (USA). FITC-conjugated secondary antibodaries were purchased from Ancell Corporation (Bayport, MN). Cell culture reagents were obtained from Life Technologies, Inc. (Rockville, MD).

\subsection{MTT assay}

The inhibition of cell proliferation was assessed by the MTT assay. Briefly, SMMC-7721, Bel-7402, HepG2, LM-3, Hepa1-6, Huh7, BGC-803, MDA-MB-435, MDA-MB-231, MCF-7, A375, A549, NCI-1975, HT-29, CT-26, and Raw 264.7 cells were seeded in 96 -well culture plates $\left(1 \times 10^{4}\right.$ cells/well/100 $\left.\mu \mathrm{l}\right)$, incubated at $37^{\circ} \mathrm{C}$ overnight to adhere, and then treated with CA1P at various concentrations for 72 hours. After incubation, a $20-\mu$ l aliquot of MTT solution $(5 \mathrm{mg} / \mathrm{ml}$ in PBS) was added 
to each well and the plates were incubated in the dark at $37^{\circ} \mathrm{C}$ for 4 hours. The medium was removed, formazan precipitates were dissolved with dimethyl sulfoxide, and the optical density was measured at $570 \mathrm{~nm}$ using an MK3 Scientific Multiskan (ThermoFisher Scientific, USA). The half maximal inhibitory concentration (IC50) was calculated according to the proliferation inhibition ratio of the cells.

\subsection{Assay of mitochondrial membrane potential (MMP)}

The HepG2 cells, which were pre-cultured in 6-well plates, were treated with CA1P $(1,10,50 \mathrm{nM})$ for 6 hours, and MMP was analyzed by JC-1 staining according to the manufacturer's instructions (MMP assay kit with JC-1, Beyotime Biotechnology, Shanghai, China). The JC-1 dye serves as an inducator of MMP; JC-1 aggregates in mitochondria exhibit red fluorescence, but membrane depolarization prevents aggregation and increases green fluorescence. After incubation, cells were washed once with PBS. The intensity of JC-1 staining was measured by fluorescence microscopy at an excitation wave length of $505 \mathrm{~nm}$ with a 534-nm emission filter (Olympus fluorescent microscope, Japan).

\subsection{ROS imaging}

ROS generation was measured by the oxidation-sensitive fluorescent probe DCFH-DA (Beyotime Biotechnology, Shanghai, China). To determine the role of ROS in cytotoxicity caused by CA1P, qualitative fluorescence microscopic analysis was performed after DCFH-DA staining. Briefly, $2 \times 10^{5}$ cells were pre-cultured in a 6-well plate for 24 hours and subsequently exposed to CA1P $(1,10,50 \mathrm{nM})$ for 6 hours. After incubation, the cells were washed with PBS and then stained with $10 \mu \mathrm{M}$ DCFH-DA for 30 minutes at $37^{\circ} \mathrm{C}$ in the dark. Cells were washed twice with chilled PBS. Positive-staining areas were photographed and analyzed with an Olympus Fluorescence Microscope (DCFH-DA excitation wavelength $488 \mathrm{~nm}$, emission wavelength $520 \mathrm{~nm}$ ). 
Cells were lysed with ice-cold lysis buffer (10 mM Tris, $1 \mathrm{mM}$ EDTA, $1 \mathrm{mM}$ DTT, $60 \mathrm{mM} \mathrm{KCl}, 0.5 \% \mathrm{v} / \mathrm{v}$ NP-40, and protease inhibitors). Protein concentration was determined with the bicinchoninic acid assay. Equal 30- $\mu$ g total protein samples were separated by electrophoresis on SDS-polyacrylamide gels and transferred to PVDF membranes at 90 volts for 45-90 minutes (Millipore, Bedford, MA). After blocking nonspecific protein binding, the membranes were incubated with primary antibodies over night at $4{ }^{\circ} \mathrm{C}$. The secondary antibodies were conjugated to horse radish peroxidase (Santa Cruz Biotechnology Inc., Dallas, USA). The detection of specific proteins was performed with an ECL western blotting kit (ECL-plus, Thermo Scientific) according to the manufacturer's protocol, and the fluorescence signals were recorded with a luminescent image analyzer (Chemi-Smart 2000, Bio-rad, USA).

\subsection{Immunofluorescence.}

HepG2 cells grown on glass coverslips were fixed in $4 \%$ paraformaldehyde. After blocking with $3 \%$ bovine serum albumin (BSA), the cells were incubated with primary antibodies for 1 hour at $37^{\circ} \mathrm{C}$. Then, the cells were washed three times $(10$ minutes each) with PBST, incubated for 1 hour at $37^{\circ} \mathrm{C}$ with Alexa-conjugated secondary antibody diluted in PBST with $0.5 \%$ BSA, and subsequently washed three times with PBST. Cell nuclei were stained with 4',6-diamidino-2-phenylindole (DAPI; Sigma Aldrich) for 5 minutes. Finally, the cells were analyzed by laser scanning confocal microscope (Olympus fluorescent microscope, Japan).

\subsection{Apoptosis assay}

CA1P-induced apoptosis was monitored under a fluorescence microscope using the Annexin V-FITC apoptosis Detection Kit (Beyotime Biotechnology, Shanghai, China) according to the manufacturer's instructions. Briefly, $3 \times 10^{5}$ cells were treated with CA1P $(0,1,10,100 \mathrm{nM})$ for 24 hours. Then, cells were harvested, washed in PBS, and incubated with Annexin $\mathrm{V}$ and propidium iodide in binding buffer at room temperature for 10 minutes in the dark. The stained cells were analyzed with an 
Olympus Fluorescence Microscope (Japan).

\subsection{Mice HCC tumor models}

For animal experiment, male athymic BALB/c nu/nu mice (5-week old), male C57BL/6 mice (6-week old), and male BALB/c mice (6-week old) were purchased from SLRC Laboratory Animal Co., Ltd. (Shanghai, China) and maintained in our animal facility for 1 week before used. Mice were housed under specific pathogen-free conditions at $24 \pm 1^{\circ} \mathrm{C}$ and $55 \pm 5 \%$ humidity in a barrier facility with 12-hour light-dark cycles. All animal experiments were performed in accordance with the National Institutes of Health Guide for the Care and Use of Laboratory Animals, with the approval of center for new drug evaluation and research, China Pharmaceutical University (Nanjing, China).

For the subcutaneous xenograft model, athymic nude mice (aged 4-6 weeks and weighing 16-18 g) were inoculated with HepG2 cells subcutaneously in the right foreleg $\left(2 \times 10^{6}\right.$ cells/mouse). When the average tumor volume approached to $100 \mathrm{~mm}^{3}$, mice were randomized into 7 groups ( $n=6$ per group) and either intravenously injected with saline, CA1P $(1,2,4 \mathrm{mg} / \mathrm{kg})$, CA4P $(40 \mathrm{mg} / \mathrm{kg})$, or paclitaxel $(10 \mathrm{mg} / \mathrm{kg})$ or given sorafenib $(30 \mathrm{mg} / \mathrm{kg})$ by gavage every other day. Tumor sizes were measured with digital calipers twice per week, and tumor volumes were calculated according to the following formula: tumor volume $=($ length $) \times(\text { width })^{2} \times 0.5$. Tumors were removed for measurement when the average volume of the control group exceeded $2,000 \mathrm{~mm}^{3}$.

The orthotopic transplantation tumor models were prepared as follows. Mice were anesthetized with $4 \%$ chloral hydrate $(0.1 \mathrm{~mL} / 10 \mathrm{~g})$ and placed in a supine position. A small transverse incision below the sternum was made to expose the liver. LM-3-GFP, Hepa 1-6, or H22 cells were suspended in $20 \mu \mathrm{l}$ PBS, which was then mixed with 50\% Matrigel (BD Biosciences) and injected into the upper left lobe liver capsule of BALB/c nu-nu or C57BL/6J mice. The abdomen was then sutured. For the LM-3 orthotopic implant tumor model, mice were randomly divided into 5 groups, including solvent control group (saline), CA1P groups $(1 \mathrm{mg} / \mathrm{kg}, 2 \mathrm{mg} / \mathrm{kg}$ and 4 
$\mathrm{mg} / \mathrm{kg}$ ) and a positive control drug group (sorafenib tosylate, $30 \mathrm{mg} / \mathrm{kg}$ ); each group contained 7 mice. This experiment was terminated after the mice were treated for 4 weeks. Antitumor efficacy was assessed by GFP fluorescence intensity detection with an in vivo imaging system (Eastman Kodak Company, Rochester, USA). For the Hepa 1-6 orthotopic implant tumor model, mice were randomly divided into 4 groups, including solvent control group (saline) and CA1P groups (1 mg/kg, $2 \mathrm{mg} / \mathrm{kg}$ and 4 $\mathrm{mg} / \mathrm{kg}$ ); each group contained 5 mice. After 4 weeks of treatment, peritoneal macrophages and peripheral blood macrophages were separated for flow cytometric analysis. Tumors were isolated, and paraffin sections were prepared for subsequent immunohistochemical analysis.

2.10 Terminal deoxynucleotidyltransferase-mediate ddUTP nick end-labeling (TUNEL) assay

Tumor tissue apoptosis was investigated with the TUNEL assay (Roche Diagnostics GmbH, Mannheim, Germany) according to the manufacturer's instructions. Quantification was performed by calculating the mean number of TUNEL-positive cell nuclei within 20 high-power (400×) fields per animal group.

\subsection{Immunohistochemistry}

Tumor specimens were fixed in formalin, dehydrated in an ethanol series, treated with xylene, and mounted in paraffin. Four-micrometer-thick tissue sections were deparaffinized, rehydrated, and incubated with $3 \% \mathrm{H}_{2} \mathrm{O}_{2}$ in methanol. Subsequently, the antigen was retrieved and sections were incubated with $1 \%$ BSA. Slides were incubated with anti-F4/80, anti-Foxp3, anti-TNF- $\alpha$, or anti-TGF- $\beta$ antibodies at $4{ }^{\circ} \mathrm{C}$ overnight. After incubation with a secondary antibody at room temperature for 60 minutes, slides were incubated with a streptavidin-peroxidase complex. The peroxidase reaction was developed with 3, 3'-diaminobenzidine and counterstained with Mayer's hematoxylin. Finally, the slides were analyzed with an inverted microscope (Olympus fluorescent microscope, Japan). 


\subsection{Bone marrow-derived macrophage (BMDM) preparation}

Bone marrow cells were isolated from the femurs and tibias of 8-10-week old male Balb/c mice by flushing the bone cavity with RPMI 1640 medium. The harvested cells were washed, plated and differentiated into TAMs by exposing the cells to macrophage differentiation media (20\% L929 cell culture supernatant, $20 \%$ Hepa 1-6 cell culture supernatant, 10\% FBS, and 50\% RPMI-1640). Macrophage differentiation was confirmed by monitoring the expression of the cell surface marker F4/80, which is preferentially expressed by mature macrophages.

\subsection{Adoptive Transfer of Macrophages}

After macrophages stimulus-induced maturation, cells were collected, diluted to $2 \times 10^{6} / \mathrm{ml}$, and intravenously administered to $\mathrm{H} 22$ orthotopic tumor model mice. The mice were randomized into the following four groups ( $\mathrm{n}=5$ per group): control (saline), CA1P (2 mg/kg), macrophages (macrophages only) and combine (both CA1P and macrophages). All mice were treated every other day for 3 weeks.

\subsection{Flow Cytometric Analysis}

Peripheral blood and peritoneal macrophages were harvested from mice bearing Hepa1-6 or H22 orthotopic tumors, respectively. To obtain mouse peritoneal macrophages, the peritoneal cavity was gently flushed with $5 \mathrm{ml}$ sterile PBS that was then harvested. Blood monocytes were separated by Histopaque ${ }^{\circledR}$ (SIGMA-ALDRICH 1083, USA). Macrophages in peripheral blood were separated by Histopaque ${ }^{\circledR}$ (SIGMA-ALDRICH, 1083). Pretreatment with blocking antibodies was performed with anti-mouse F4/80 (eBioscience) and CD11b (eBioscience) at 0.5 $\mu \mathrm{g}$ per test. Staining was assessed with a Amnis Flowsight (Millipore). Samples were compensated and analyzed using Amnis IDEAS software.

\subsection{Statistical analysis and experiment repeat}

Data were analyzed for statistical significance using the two-tailed unpaired t test and One-Way ANOVA (GraphPad Software, San Diego, CA). In these analyses, p 
values $<0.05$ were considered to be significant. ${ }^{*} \mathrm{P}<0.05,{ }^{* *} \mathrm{P}<0.01$ and ${ }^{* * *} \mathrm{P}<0.001$. All the experiments in vitro had been comfirmed for three times and the animal number we used for in-vivo experiments was at least 5 .

\section{Results}

\subsection{CA1P inhibited the growth of various tumor cell lines in vitro}

Initial experiments were conducted to evaluate the growth inhibition by CA1P of various human cancer cell lines including hepatocellular carcinoma SMMC-7721, Bel-7402, HepG2, LM-3, Hepa 1-6, and Huh7 cells, gastric carcinoma BGC-803 cells, breast carcinoma MDA-MB-231, and MCF-7 cells, colorectal carcinoma HT-29, and CT-26 cells, lung carcinoma A375, A549, and NCI-1975 cells. Most HCC cell lines we tested were sensitive to CA1P with a small IC50 value less than $50 \mathrm{nM}$ (Table 1).

\subsection{CA1P induced hepatocellular carcinoma cell apoptosis in vitro and in vivo}

To investigate the effect of CA1P on hepatic carcinoma cell apoptosis, HepG2 cells were treated with CA1P at $1 \mathrm{nM}, 5 \mathrm{nM}$, or $10 \mathrm{nM}$ for 24 hours, and the protein levels of Mcl-1 and Bcl-2 were monitored. At 10 nM, CA1P significantly decreased Mcl-1 expression, but the Bcl-2 level was unchanged (Fig. 1A). JC-1 dye was used to assess the mitochondrial membrane potential (MMP) of HepG2 cells. As shown in Fig. 1B, 6 hours of HepG2 cell treatment with CA1P $(1,10,50 \mathrm{nM})$ caused significant accumulation of green fluorescence, indicating a decrease of MMP. To explore the upstream regulatory mechanisms leading to CA1P-induced mitochondrial dysfunction, intracellular ROS levels were examined by DCFH-DA staining. HepG2 cells treated with CA1P $(1,10,50 \mathrm{nM})$ for 6 hours showed a dose-dependent ROS accumulation compared with the control group (Fig. 1C).

To assess apoptosis induction by CA1P in tumor cells in vivo, an orthotopic hepatocellular carcinoma mouse model of LM-3-GFP cells was established, and CA1P ( $2 \mathrm{mg} / \mathrm{kg}$ ) was administered by tail vein every other day (duration of 21 days).

The TUNEL assay was performed on tumor tissue paraffin section from the orthotopic model mice. As shown in Fig. 1D, LM-3-GFP tumor tissue from the 2 
$\mathrm{mg} / \mathrm{kg}$ CA1P group showed enhanced apoptosis compared to control treatment.

3.3 CA1P induced tumor cell apoptosis by microtubule depolymerization-induced AKT inactivation and the removal of GSK-3 $\beta$ inhibition

The results indicated that CA1P induced HepG2 cell apoptosis by decreasing Mcl-1 levels rather than Bcl-2 (Fig. 1A). Mcl-1 can be phosphorylated by GSK-3 $\beta$ at Ser159, which results in Mcl-1 ubiquitination and rapid proteasomal degradation [26-28]. Here, we studied the levels of GSK-3 $\beta$ phosphorylation on Ser9, which is the main phosphorylation site for GSK-3 $\beta$ inhibition in HepG2 cells. The results revealed that CA1P treatment $(10 \mathrm{nM})$ reduced p-GSK $3 \beta$ (Ser9) without altering total GSK-3 $\beta$ protein levels, indicating an activation of GSK-3 $\beta$ (Fig. 2A). Because AKT phosphorylates GSK-3 $\beta$ on Ser9 and leads to GSK-3 $\beta$ inactivation, the protein levels of p-AKT and total AKT were determined. CA1P reduced AKT phosphorylation on Ser473 without an obvious change in the total AKT protein levels (Fig. 2A), suggesting that CA1P activated GSK-3 $\beta$ by down-regulating AKT phosphorylation and subsequently increased the ubiquitination and degradation of Mcl-1.

GSK-3 $\beta$ plays a critical role in $\mathrm{Wnt} / \beta$-catenin signaling, which is abnormally activated during $\mathrm{HCC}$ development. In this study, $\beta$-catenin expression was dramatically reduced after CA1P treatment monitored by WB and immunofluorescence assay, suggesting that CA1P also inhibited the Wnt/ $\beta$-catenin pathway in HepG2 cells by -activating of GSK-3 $\beta$ (Figs. 2A \& 2B). To further explore the mechanism of AKT regulation by CA1P, the microtubule-binding protein dynactin p150 was detected with WBs. It has been reported that microtubule disaggregation specifically deactivates AKT signaling via dynactin $\mathrm{p} 150$, which is a direct target of AKT [25]. As shown in Fig. 2A, CA1P inhibited AKT phosphorylation by downregulation of dynactin p150 expression similarly as an anti-microtubule drug.

To determine whether the removal of GSK-3 $\beta$ inhibition is required for apoptosis induction by CA1P, the GSK-3 $\beta$ inhibitor CHIR-99021 was used. The pretreatment of HepG 2 cells with $3 \mu \mathrm{M}$ CHIR-99021 for 12 hours blocked the reduction of Mcl-1 and 
$\beta$-catenin induced by CA1P in HepG2 cells with no significant changes in dynactin p150 or p-AKT protein levels (Fig. 2C). Apoptosis assays also showed that CHIR-99021 partly reversed the apoptosis induced by CA1P (Fig. 2D). These findings collectively suggested that CA1P induced AKT inactivation through the microtubule-dynactin p150 pathway, which led to GSK-3 $\beta$ activation and the down-regulation of Mcl-1 and $\beta$-catenin and ultimately resulted in tumor cell apoptosis.

\subsection{CA1P inhibited hepatocellular carcinoma in xenograft tumor models}

To further assess the antitumor activity of CA1P on hepatocellular carcinoma in vivo, a HepG2 subcutaneous xenograft model and an LM-3 orthotopic xenograft model were used. HepG2 subcutaneous tumors were excised and measured directly with a Vernier caliper. LM-3-GFP tumors were first measured by detecting the fluorescence intensity of GFP using an invivo imaging system and then excised and measured after 4 weeks of treatment. The administration of CA1P at $2 \mathrm{mg} / \mathrm{kg}$ or 4 $\mathrm{mg} / \mathrm{kg}$ resulted in a significant tumor volume reduction in both models compared to control groups (Figs. 3A-C). The fluorescence image of LM-3-GFP tumors also showed a corresponding tumor-suppression trend. To confirm the tumor inhibition mechanism regulated by CA1P, LM-3-GFP tumor tissue protein was prepared, and the Wnt pathway-related proteins was analyzed. WBs revealed significant changes in the expression of Wnt pathway molecules in tumor tissues from CA1P treated mice, including a decrease of $\mathrm{p}-\mathrm{AKT}^{\mathrm{Ser} 473}, \mathrm{p}$-GSK $3 \beta^{\mathrm{Ser} 9}, \beta$-catenin, and the Wnt regulatory protein c-myc (Fig. 3D). These results suggested that CA1P effectively inhibited the tumor development in vivo via the same mechanism that was discovered in vitro.

\subsection{TAMs elimination was involved in CA1P induced HCC regression}

The HCC microenvironment plays a critical role during tumor development, and TAMs and Tregs are two main immunosuppressive cell types that accelerate tumor growth. To determine whether CA1P altered the TME, a Hepa 1-6 liver orthotopic xenograft model was established. After 4 weeks of treatment with CA1P, tumors were 
separated, and paraffin sections were prepared. Immunohistochemistry showed that the infiltration of macrophages and Tregs in the tissue microenvironment was obviously decreased in the CA1P group (Fig. 4A). Furthermore, CA1P decreased the expression of the inflammatory cytokines TNF- $\alpha$ and TGF- $\beta$ (Fig. 4B), two vital tumor-associated cytokines in the microenvironment. These results suggested that CA1P altered the TME by disrupting the crosstalk between tumor cells and tumor-associated immune cells.

To assess whether the targeting of TAMs plays a major role in the antitumor activity of CA1P, BMDMs were differentiated into TAMs by exposing cells to conditioning medium containing $\mathrm{H} 22$ culture supernatant and then adoptively transferred to the mice of a new H22 liver orthotopic xenograft model after each drug treatment. Similar to the other HCC models studied, CA1P obviously inhibited the growth of H22 liver tumors. However, the transfer of bone marrow-derived in vitro-differentiated macrophages reinstated tumor growth to some degree in CA1P-treated mice (Fig. 4C). Flow cytometry and immunofluorescence assays further revealed that the adoptive transfer of TAMs partly restored the number of macrophages in peripheral blood and the TME (Fig. 4D \& 4E). Overall, these results are consistent with the view that targeting TAMs was, at least in part, responsible for the antitumor activity of CA1P under these conditions.

3.6 CA1P induced macrophage apoptosis through the down-regulation of the Wnt/B-catenin pathway and Mcl-1

During innate and adaptive immunity, cells are recruited to the tumor site, and macrophages are particularly abundant at all stages of tumor progression in the liver. In the TME, macrophages are reprogrammed as TAMs with pro-tumor roles. To further study the impact of CA1P on TAMs, macrophages in peripheral blood and peritoneal macrophages were separated from Hepa 1-6 orthotopic model mice, and detected by flow cytometry using anti-CD11b and anti-F4/80 antibodies. CA1P observably eliminated TAMs in tumor-bearing mice (Fig. 5A). To confirm the apoptosis of TAM induced by CA1P in vitro, bone marrow cells were isolated from 
the femurs and tibias of Balb/c mice and differentiated into TAMs by exposing cells to conditioning medium containing 20\% L929 cell culture supernatant, 20\% Hepa 1-6 cell culture supernatant, 10\% FBS, and 50\% RPMI-1640. Annexin V/PI staining revealed that significant cell apoptosis occurred after treated with $10 \mathrm{nM} \mathrm{CA1P}$, and the apoptosis could be partly reversed by CHIR 99021, indicating that CA1P induced the apoptosis of tumor cells and TAMs through the same pathway (Fig. 5B). Subsequently, WB analysis of Raw 264.7 cells revealed that CA1P also down-regulated p-AKT, Mcl-1, and Wnt/ $\beta$-catenin pathway-related proteins including GSK-3 $\beta^{\text {Ser9 }}$ and $\beta$-catenin, which could also be abolished by pre-treatment of CHIR-99021 (Fig. 5C).

\section{Discussion}

HCC is the sixth most common neoplasm in the world and the second most common malignancy in China, ranking third in cancer-related mortality [29]. However, no effective drugs for this disease have been identified to date and new drugs targeting a variety of mechanisms in HCC cell s are needed for therapy.

CA1P is a microtubule assembly inhibitor that binds to the colchicine-binding site of $\beta$-tubulin. It blocks the tumor vessels growth by inhibiting the polymerization of microtubule resulted in tumor regression. Furthermore, CA1P becomes CA1 after dissolution, and CA1 can be oxidized to quinones Q1 and Q2, which directly destroy intracellular proteins and nucleic acids and can activate oxidative stress pathways in tumor cells [30]. Several clinical trials testing CA1P as a vascular disrupting agent in solid cancer are in progress [31, 32].

In this study, we found most HCC cell lines we tested were sensitive to CA1P with a small IC50 value less than $50 \mathrm{nM}$ (Table 1) and the inhibitory rate of tumor growth in four HCC models in vivo exceeded $60 \%$ after CA1P treatment at $2 \mathrm{mg} / \mathrm{kg}$. Further studies revealed that CA1P caused microtubule inhibition-induced AKT inactivation, the subsequent removal of GSK-3 $\beta$ inhibition, and the down-regulation of $\beta$-catenin and Mcl-1, whereby elimiating both HCC cells and TAMs. This novel findings demonstrate that CA1P is more than a simple vascular disrupting agent. 
The previous studies show that HCC develops from a normal hepatocyte or precursor cell type to a transformed phenotype due to the accumulation of aberrant genetic and epigenetic changes and the activation of growth factor signaling pathways [33-37]. Recently, a wealth of genomics studies in HCC have shown that the Wnt/ $\beta$-catenin pathway is a major oncogenic driver that plays a crucial role in HCC tumorigenesis and development [38-42]. It is noteworthy that Huh7 cells was relatively insensitive to CA1P but still have an IC50 less than $1 \mu \mathrm{M}$. Previous study has showed that Huh7 cells have reduced $\beta$-catenin activation compared to HepG2, SNU398 and SNU387 cells, which may explain this result [43]. The discrepant level of Wnt/ $\beta$-catenin pathway activation might be the reason for the different sensitivities to CA1P between Huh7 cells and other HCC cells we tested. Further experimental evidence is needed to confirm this hypothesis.

At present, TME-targeted drugs are receiving increasing attention because the TME is a complex cell network that evolves with tumor progression and provides supports to tumor cells during the transition to malignancy. Tumors can influence the microenvironment by releasing extracellular signals, promoting tumor angiogenesis, and inducing peripheral immune tolerance, and the immune cells in the microenvironment can affect the growth and evolution of cancer cells, through mechanisms such as immuno-editing. In the HCC microenvironment, macrophages are one of the most prevalent immune cell types interacting with the tumor and generally play protumoral roles such as angiogenesis promoting and drug resistance at all stages of tumor progression $[19,44-46]$. At present sorafenib is the only systemic standard of care for advanced HCC patients with a mean survival benefit of only 3 months $[1,3,38,41]$. However, some preclinical findings have revealed that sorafenib may increase the invasiveness and metastatic behavior of tumor cellsdue to a significant increase in the recruitment of TAMs, which leads to resistance [47]. Thus, the influence of the TME, especially the existence of TAMs, should be taken into account. In this study, we found that CA1P could eliminate TAMs and Tregs accompanied by the reduction of TGF- $\beta$ and TNF- $\alpha$ expression. These data indicated that CA1P would most likely receive a good curative effect with decreased drug 
resistance compared with sorafenib.

Collectively, our results indicate that CA1P exerted remarkable antitumor activity against hepatocarcinoma by inducing apoptosis of HCC cells together with TAMs, which was probably due to the inhibition on the $\mathrm{Wnt} / \beta$-catenin pathway that occurs upon blocking the microtubule-dynactin p150-AKT-GSK3 $\beta$ pathway. CA1P inhibited tubulin polymerization and disrupted the interaction between dynactin p150 and p-AKT, thus causing the dephosphorylation and activation of GSK-3 $\beta$. Subsequently, $\beta$-catenin phosphorylation and degradation was increased, and the Wnt/ $\beta$-catenin pathway was inhibited. Activation of GSK-3 $\beta$ also induced the degradation of Mcl-1, but does not affect Bcl-2 (Fig. 6). Thus, we indicated that CA1P is a promising new drug targeting on the Wnt/ $\beta$-catenin pathway and it may achieve pronounced therapeutic efficacy in $\mathrm{HCC}$, especially when the Wnt/ $\beta$-catenin pathway is constitutively activated.

\section{Acknowledgements}

This work was supported in part by the National Science Foundation of China (No.91529304, 81473230, 81273547, 81403020 and 91129731), the Natural Science Foundation of Jiangsu Province (No. BK2012025) and Foundation of Nanjing University of Chinese Medicine (13XZR19).

\section{Conflict of interest}

The authors do not have any conflict of interest.

\section{References}

[1] J. Bruix, G.J. Gores, V. Mazzaferro, Hepatocellular carcinoma: clinical frontiers and perspectives, Gut, 63 (2014) 844-855.

[2] G. Giannelli, B. Rani, F. Dituri, Y. Cao, G. Palasciano, Moving towards personalised therapy in patients with hepatocellular carcinoma: the role of the microenvironment, Gut, 63 (2014) 1668-1676.

[3] J. Bruix, J.L. Raoul, M. Sherman, V. Mazzaferro, L. Bolondi, A. Craxi, P.R. Galle, A. Santoro, M. Beaugrand, A. Sangiovanni, C. Porta, G. Gerken, J.A. Marrero, A. Nadel, M. Shan, M. Moscovici, D. Voliotis, J.M. Llovet, Efficacy and safety of sorafenib in patients with advanced hepatocellular 
carcinoma: subanalyses of a phase III trial, Journal of hepatology, 57 (2012) 821-829.

[4] R. Tateishi, M. Omata, Hepatocellular carcinoma in 2011: Genomics in hepatocellular carcinoma--a big step forward, Nature reviews. Gastroenterology \& hepatology, 9 (2012) 69-70.

[5] J.M. Ebos, C.R. Lee, W. Cruz-Munoz, G.A. Bjarnason, J.G. Christensen, R.S. Kerbel, Accelerated metastasis after short-term treatment with a potent inhibitor of tumor angiogenesis, Cancer cell, 15 (2009) 232-239.

[6] S. Loges, M. Mazzone, P. Hohensinner, P. Carmeliet, Silencing or fueling metastasis with VEGF inhibitors: antiangiogenesis revisited, Cancer cell, 15 (2009) 167-170.

[7] M. Paez-Ribes, E. Allen, J. Hudock, T. Takeda, H. Okuyama, F. Vinals, M. Inoue, G. Bergers, D. Hanahan, O. Casanovas, Antiangiogenic therapy elicits malignant progression of tumors to increased local invasion and distant metastasis, Cancer cell, 15 (2009) 220-231.

[8] J. Chen, J. Liu, R. Jin, J. Shen, Y. Liang, R. Ma, H. Lin, X. Liang, H. Yu, X. Cai, Cytoplasmic and/or nuclear expression of beta-catenin correlate with poor prognosis and unfavorable clinicopathological factors in hepatocellular carcinoma: a meta-analysis, PloS one, 9 (2014) e111885.

[9] A. Villanueva, P. Newell, D.Y. Chiang, S.L. Friedman, J.M. Llovet, Genomics and signaling pathways in hepatocellular carcinoma, Seminars in liver disease, 27 (2007) 55-76.

[10] C.Y. Logan, R. Nusse, The Wnt signaling pathway in development and disease, Annual review of cell and developmental biology, 20 (2004) 781-810.

[11] B.T. MacDonald, K. Tamai, X. He, Wnt/beta-catenin signaling: components, mechanisms, and diseases, Developmental cell, 17 (2009) 9-26.

[12] H. Clevers, Wnt/beta-catenin signaling in development and disease, Cell, 127 (2006) 469-480.

[13] S. Angers, R.T. Moon, Proximal events in Wnt signal transduction, Nature reviews. Molecular cell biology, 10 (2009) 468-477.

[14] H. Yuzugullu, K. Benhaj, N. Ozturk, S. Senturk, E. Celik, A. Toylu, N. Tasdemir, M. Yilmaz, E. Erdal, K.C. Akcali, N. Atabey, M. Ozturk, Canonical Wnt signaling is antagonized by noncanonical Wnt5a in hepatocellular carcinoma cells, Molecular cancer, 8 (2009) 90.

[15] A. Bengochea, M.M. de Souza, L. Lefrancois, E. Le Roux, O. Galy, I. Chemin, M. Kim, J.R. Wands, C. Trepo, P. Hainaut, J.Y. Scoazec, L. Vitvitski, P. Merle, Common dysregulation of Wnt/Frizzled receptor elements in human hepatocellular carcinoma, British journal of cancer, 99 (2008) 143-150.

[16] J.R. Wands, M. Kim, WNT/beta-catenin signaling and hepatocellular carcinoma, Hepatology, 60 (2014) 452-454.

[17] K. Breuhahn, P. Schirmacher, Signaling networks in human hepatocarcinogenesis--novel aspects and therapeutic options, Progress in molecular biology and translational science, 97 (2010) 251-277.

[18] M. Geng, Y.C. Cao, Y.J. Chen, H. Jiang, L.Q. Bi, X.H. Liu, Loss of Wnt5a and Ror2 protein in hepatocellular carcinoma associated with poor prognosis, World journal of gastroenterology: WJG, 18 (2012) 1328-1338.

[19] J. Condeelis, J.W. Pollard, Macrophages: obligate partners for tumor cell migration, invasion, and metastasis, Cell, 124 (2006) 263-266.

[20] D. Capece, M. Fischietti, D. Verzella, A. Gaggiano, G. Cicciarelli, A. Tessitore, F. Zazzeroni, E. A,esse, The inflammatory microenvironment in hepatocellular carcinoma: a pivotal role for tum or-associated macrophages. BioMed research international, 2013 (2013) 187204. 
[21] QM. Fan, YY. Jing, GF. Yu, XR. Kou, F. Ye, L. Gao, R. Li, QD. Zhao, Y. Yang, ZH. Lu, LX. Wei, Tumor-associated macrophages promote cancer stem cell-like properties via transforming growth factor-beta1-induced epithelial-mesenchymal transition in hepatocellular carcinoma, Cancer letters, 352 (2014) 160-8.

[22] ML. Macheda, SA. Stacker, Importance of Wnt Signaling in the Tumor Stroma Microenvironment, Current Cancer Drug Targets, 8 (2008) 454-465

[23] LM. Greene, MJ. Meegan, DM. Zisterer, Combretastatins: More Than Just Vascular Targeting Agents? Journal of pharmacology and experimental therapeutics, 355 (2015) 212-227.

[24] J. Hua, Y. Sheng, KG. Pinney, CM. Garner, RR. Kane, JA. Prezioso, GR. Pettit, DJ. Chaplin, K. Edvardsen, Oxi4503, a novel vascular targeting agent: effects on blood flow andantitumor activity in comparison to combretastatin A-4 phosphate, Anticancer Res, Mar-Apr (2B) (2003) 1433-40.

[25] H. Jo, F. Loison, H.R. Luo, Microtubule dynamics regulates Akt signaling via dynactin p150, Cellular signalling, 26 (2014) 1707-1716.

[26] Q. Ding, X. He, J.M. Hsu, W. Xia, C.T. Chen, L.Y. Li, D.F. Lee, J.C. Liu, Q. Zhong, X. Wang, M.C. Hung, Degradation of Mcl-1 by beta-TrCP mediates glycogen synthase kinase 3-induced tumor suppression and chemosensitization, Molecular and cellular biology, 27 (2007) 4006-4017.

[27] H. Inuzuka, S. Shaik, I. Onoyama, D. Gao, A. Tseng, R.S. Maser, B. Zhai, L. Wan, A. Gutierrez, A.W. Lau, Y. Xiao, A.L. Christie, J. Aster, J. Settleman, S.P. Gygi, A.L. Kung, T. Look, K.I. Nakayama, R.A. DePinho, W. Wei, SCF(FBW7) regulates cellular apoptosis by targeting MCL1 for ubiquitylation and destruction, Nature, 471 (2011) 104-109.

[28] C. Peddaboina, D. Jupiter, S. Fletcher, J.L. Yap, A. Rai, R.P. Tobin, W. Jiang, P. Rascoe, M.K. Rogers, W.R. Smythe, X. Cao, The downregulation of Mcl-1 via USP9X inhibition sensitizes solid tumors to Bcl-xl inhibition, BMC cancer, 12 (2012) 541.

[29] J. Ferlay, H.R. Shin, F. Bray, D. Forman, C. Mathers, D.M. Parkin, Estimates of worldwide burden of cancer in 2008: GLOBOCAN 2008, International journal of cancer. Journal international du cancer, 127 (2010) 2893-2917.

[30] LK. Folkes, M. Christlieb, E. Madej, MR. Stratford, P. Wardman P, Oxidative metabolism of combretastatin A-1 produces quinone intermediates with the potential to bind to nucleophiles and to enhance oxidative stress via free radicals, Chemical research in toxicology, 20 (2007) 1885-94.

[31] DM. Patterson, M. Zweifel, MR. Middleton, PM. Price, LK. Folkes, MR. Stratford, P. Ross, S. Halford, J. Peters, J. Balkissoon, DJ. Chaplin, AR. Padhani, GJ. Rustin, Phase I clinical and pharmacokinetic evaluation of the vascular-disrupting agent $\mathrm{OXi} 4503$ in patients with advanced solid tumors, Clinical cancer research : an official journal of the American Association for Cancer Research, 18 (2012) 1415-25.

[32] RP. Tanpure, BL. Nguyen, TE. Strecker, S. Aguirre, S. Sharma, DJ. Chaplin, BG. Siim, E. Hamel, JW. Lippert, GR. Pettit, ML. Trawick, KG. Pinney, Regioselective synthesis of water-soluble monophosphate derivatives of combretastatin A-1, Journal of natural products, 74 (2011) 1568-74.

[33] D.F. Calvisi, S. Ladu, A. Gorden, M. Farina, J.S. Lee, E.A. Conner, I. Schroeder, V.M. Factor, S.S. Thorgeirsson, Mechanistic and prognostic significance of aberrant methylation in the molecular pathogenesis of human hepatocellular carcinoma, The Journal of clinical investigation, 117 (2007) 2713-2722.

[34] Y. Hoshida, A. Villanueva, M. Kobayashi, J. Peix, D.Y. Chiang, A. Camargo, S. Gupta, J. Moore, M.J. Wrobel, J. Lerner, M. Reich, J.A. Chan, J.N. Glickman, K. Ikeda, M. Hashimoto, G. Watanabe, M.G. Daidone, S. Roayaie, M. Schwartz, S. Thung, H.B. Salvesen, S. Gabriel, V. 
Mazzaferro, J. Bruix, S.L. Friedman, H. Kumada, J.M. Llovet, T.R. Golub, Gene expression in fixed tissues and outcome in hepatocellular carcinoma, The New England journal of medicine, 359 (2008) 1995-2004.

[35] H.C. Lee, M. Kim, J.R. Wands, Wnt/Frizzled signaling in hepatocellular carcinoma, Frontiers in bioscience : a journal and virtual library, 11 (2006) 1901-1915.

[36] K. Revill, T. Wang, A. Lachenmayer, K. Kojima, A. Harrington, J. Li, Y. Hoshida, J.M. Llovet, S. Powers, Genome-wide methylation analysis and epigenetic unmasking identify tumor suppressor genes in hepatocellular carcinoma, Gastroenterology, 145 (2013) 1424-1435 e1421-1425.

[37] L. Zender, W. Xue, J. Zuber, C.P. Semighini, A. Krasnitz, B. Ma, P. Zender, S. Kubicka, J.M. Luk, P. Schirmacher, W.R. McCombie, M. Wigler, J. Hicks, G.J. Hannon, S. Powers, S.W. Lowe, An oncogenomics-based in vivo RNAi screen identifies tumor suppressors in liver cancer, Cell, 135 (2008) 852-864.

[38] Z. Kan, H. Zheng, X. Liu, S. Li, T.D. Barber, Z. Gong, H. Gao, K. Hao, M.D. Willard, J. Xu, R. Hauptschein, P.A. Rejto, J. Fernandez, G. Wang, Q. Zhang, B. Wang, R. Chen, J. Wang, N.P. Lee, W. Zhou, Z. Lin, Z. Peng, K. Yi, S. Chen, L. Li, X. Fan, J. Yang, R. Ye, J. Ju, K. Wang, H. Estrella, S. Deng, P. Wei, M. Qiu, I.H. Wulur, J. Liu, M.E. Ehsani, C. Zhang, A. Loboda, W.K. Sung, A. Aggarwal, R.T. Poon, S.T. Fan, J. Wang, J. Hardwick, C. Reinhard, H. Dai, Y. Li, J.M. Luk, M. Mao, Whole-genome sequencing identifies recurrent mutations in hepatocellular carcinoma, Genome research, 23 (2013) 1422-1433.

[39] L. Lin, D. Wang, N. Cao, Y. Lin, Y. Jin, C. Zheng, Whole-transcriptome analysis of hepatocellular carcinoma, Medical oncology, 30 (2013) 736.

[40] L.C. Lu, Y.Y. Shao, Y.H. Lee, M.S. Hsieh, C.H. Hsiao, H.H. Lin, H.F. Kao, Y.Y. Ma, F.C. Yen, A.L. Cheng, C.H. Hsu, beta-catenin (CTNNB1) mutations are not associated with prognosis in advanced hepatocellular carcinoma, Oncology, 87 (2014) 159-166.

[41] J.U. Marquardt, P.R. Galle, A. Teufel, Molecular diagnosis and therapy of hepatocellular carcinoma (HCC): an emerging field for advanced technologies, Journal of hepatology, 56 (2012) 267-275.

[42] N. Nishida, M. Kudo, Recent advancements in comprehensive genetic analyses for human hepatocellular carcinoma, Oncology, 84 Suppl 1 (2013) 93-97.

[43] A. Lachenmayer, C. Alsinet, R Savic, L. Cabellos, S. Toffanin, Y. Hoshida, A. Villanueva, B. Minguez, P. Newell, HW. Tsai, J. Barretina, S Thung, SC. Ward, J. Bruix, V. Mazzaferro, M. Schwartz, SL. Friedman, JM. Llovet, Wnt-pathway activation in two molecular classes of hepatocellular carcinoma and experimental modulation by sorafenib, Clinical cancer research: an official journal of the American Association for Cancer Research, 18 (2012) 4997-5007

[44] B.Z. Qian, J.W. Pollard, Macrophage diversity enhances tumor progression and metastasis, Cell, 141 (2010) 39-51.

[45] P.G. Traves, A. Luque, S. Hortelano, Macrophages, inflammation, and tumor suppressors: ARF, a new player in the game, Mediators of inflammation, 2012 (2012) 568783.

[46] C. Steidl, T. Lee, S.P. Shah, P. Farinha, G. Han, T. Nayar, A. Delaney, S.J. Jones, J. Iqbal, D.D. Weisenburger, M.A. Bast, A. Rosenwald, H.K. Muller-Hermelink, L.M. Rimsza, E. Campo, J. Delabie, R.M. Braziel, J.R. Cook, R.R. Tubbs, E.S. Jaffe, G. Lenz, J.M. Connors, L.M. Staudt, W.C. Chan, R.D. Gascoyne, Tumor-associated macrophages and survival in classic Hodgkin's lymphoma, The New England journal of medicine, 362 (2010) 875-885.

[47] W. Zhang, XD. Zhu, HC. Sun, YQ Xiong, PY. Zhuang, HX. Xu, LQ Kong, L Wang, WZ. Wu, ZY. 
Tang, Depletion of tumor-associated macrophages enhances the effect of sorafenib in metastatic liver cancer models by antimetastatic and antiangiogenic effects, Clinical cancer research: an official journal of the American Association for Cancer Research, 16 (2010) 3420-30. 


\section{Figure legends:}

Fig. 1. CA1P induces tumor cell apoptosis in vitro and in vivo. (A) Western blot analysis for Mcl-1, Bcl-2 and Cyclin B1 after HepG2 cells were treated with CA1P, CA4P, or paclitaxel for 24 hours. (B) Mitochondrial membrane depolarization analysis was performed by detecting the mitochondrial transmembrane potential using JC-1 staining after HepG2 cells were treated with CA1P, CA4P, or paclitaxel for 6 hours. (C) Intracellular ROS level detection by DCFH-DA staining after HepG2 cells were treated with CA1P, CA4P or paclitaxel for 6 hours. Data are presented as the means $\pm \mathrm{SD}, * \mathrm{p}<0.05, * * * \mathrm{p}<0.001$. (D) TUNEL assay for detecting the apoptosis in tumor tissues from the hepatocellular carcinoma LM-3 orthotopic tumor model.

Fig. 2. CA1P induces tumor cell apoptosis by microtubule depolymerization-induced AKT inactivation and the removal of GSK-3 $\beta$ inhibition. (A) Western blot analysis of dynactin p150-AKT pathway and Wnt/ $\beta$-catenin pathway after HepG2 cells were treated with CA1P for 24 hours. (B) Immunofluorescence assay for the expression of $\beta$-catenin after HepG2 cells were treated with CA1P for 24 hours. (C) Western blot analysis of dynactin p150-AKT pathway and Wnt/ $\beta$-catenin pathway after HepG2 cells were treated with CA1P for 24 hours. HepG2 cells were divided into two groups and pretreated with the GSK-3 $\beta$-specific inhibitor CHIR-99021 or normal medium for 12 hours. CA1P was then administered at a concentration of 1,5 , or $10 \mathrm{nM}$. (D) Fluorescence assay for Annexin V and PI to detect the apoptosis of HepG2 cells after treatment with CA1P for 24 hours. HepG2 cells were pretreated as mentioned above, and CA1P was subsequently administered at a concentration of 10 or $20 \mathrm{nM}$.

Fig. 3. CA1P inhibits hepatocellular carcinoma in xenograft tumor models. (A \& B) Photos of tumors excised from HepG2 subcutaneous xenograft model and LM-3 liver orthotopic xenograft model mice. (C) Statistical analysis of the tumor volume. Data are presented as the means $\pm \mathrm{SD}, * \mathrm{p}<0.05, * * \mathrm{p}<0.01, * * * \mathrm{p}<0.001$. (D) Image of LM-3-GFP tumor fluorescence intensity detected by in-vivo imaging system. (E) Western blot analysis of p-AKT and Wnt pathway-related proteins in LM-3 tumor 
tissues.

Fig. 4. TAMs elimination was involved in CA1P-induced HCC regression. (A) Hepa 1-6 liver orthotopic xenograft model was established and mice were administered with CA1P or saline for 4 weeks. Tumors were separated, and paraffin sections were prepared. The expression of TAM marker F4/80 and Treg marker Foxp3 was examined by immunochemistry. (B) The expression of TNF- $\alpha$ and TGF- $\beta$ in the microenvironment was examined by immunochemistry using specific antibodies. (C) A new H22 liver orthotopic xenograft model was established. Adoptive transfer of bone marrow-derived in vitro-differentiated macrophages into mice bearing H22 orthotopic tumors reinstated tumor growth. Macrophages $\left(2 \times 10^{6} /\right.$ mouse $)$ were intravenously injected to treated and untreated mice for 3 weeks. Photos and tumor volumes of H22 orthotopic tumors in each group. Data are presented as the means \pm SD. Compared with the control group, $* \mathrm{p}<0.05, * * \mathrm{p}<0.01, * * * \mathrm{p}<0.001$; compared with the CA1P group, \#p < 0.05. (D) Flow cytometry analysis to assess the quantity of macrophages in the peripheral blood from the mice of the H22 orthotopic implant tumor model. (E) Immunofluorescence assay to assess the infiltration of TAMs in the TME.

Fig. 5. CA1P induced macrophage apoptosis through the down-regulation of the Wnt/ $\beta$-catenin pathway and Mcl-1. (A) Flow cytometry analysis to count the number of peripheral blood macrophages and peritoneal macrophages of Hepa 1-6 orthotopic tumor model mice. (B) Annexin V and PI staining to detect the apoptosis of BMDMs after treatment with CA1P for 24 hours. BMDMs were pretreated with GSK-3 $\beta$ specific inhibitor CHIR-99021 or control medium for 12 hours and then exposed to 1, 10 or $100 \mathrm{nM}$ CA1P, respectively. (C) Western blot analysis of p-AKT, p-GSK, $\beta$-catenin, and Mcl-1 after Raw 264.7 cells were treated with CA1P for 24 hours. Raw 264.7 cells were also pretreated with CHIR-99021 as above.

Fig. 6. Cartoon illustrating of CA1P induced signaling pathway of cell apoptosis. 
CA1P blocked the MT-dynactin p150-AKT-GSK3 $\beta$ pathway and ultimately induced apoptosis in hepatocellular carcinoma cells and macrophages. In hepatocellular carcinoma cells and macrophages, CA1P inhibited tubulin polymerization and hindered the interactions between dynactin p150 and p-AKT with the dephosphorylation and activation of GSK-3ß. Subsequently, the phosphorylation and degradation of $\beta$-catenin was increased, and $\mathrm{Wnt} / \beta$-catenin pathway was inhibited. Activating GSK-3 $\beta$ also increased the degradation of Mcl-1 and ultimately induced the apoptosis of hepatocellular carcinoma cells and macrophages. 


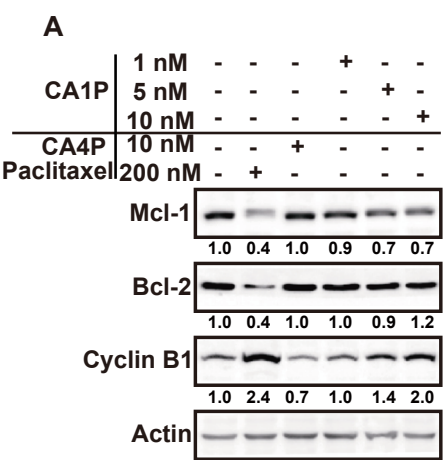

B

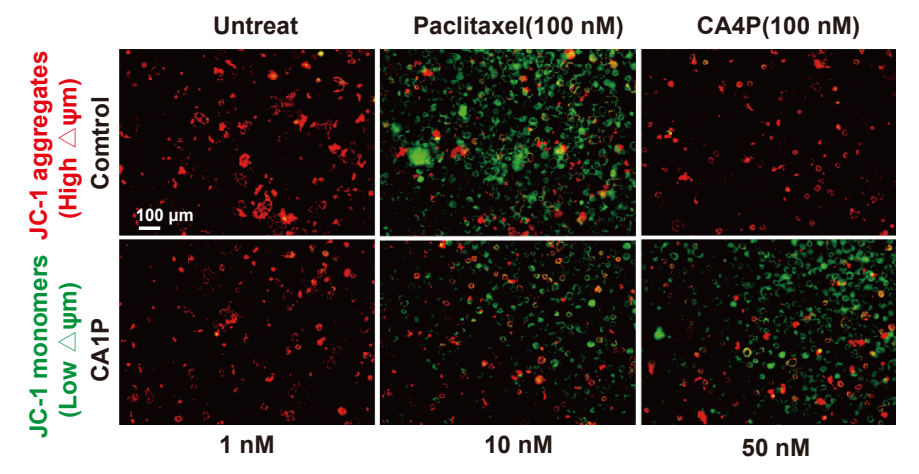

C

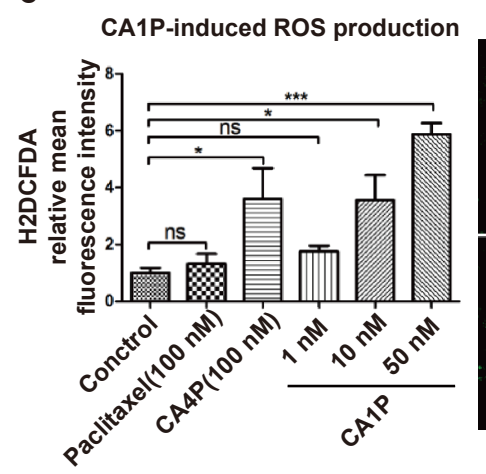

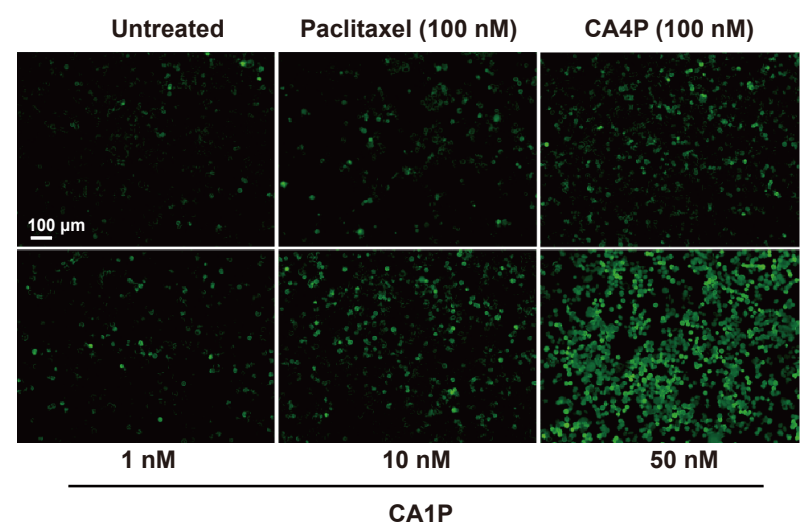

D
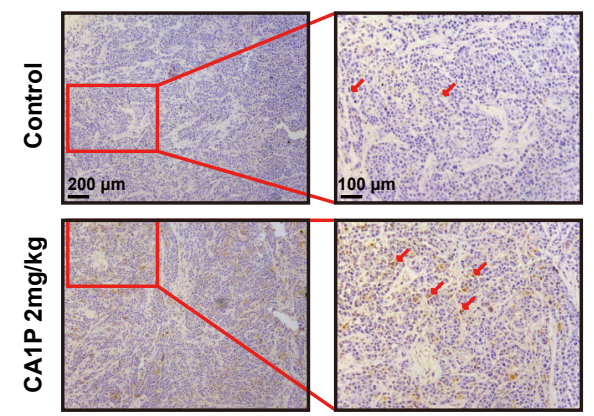
A

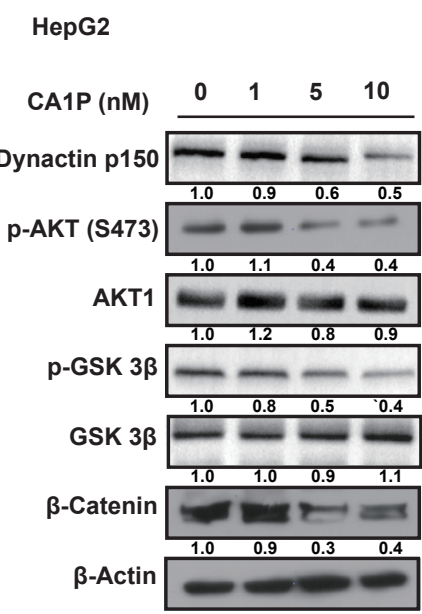

B

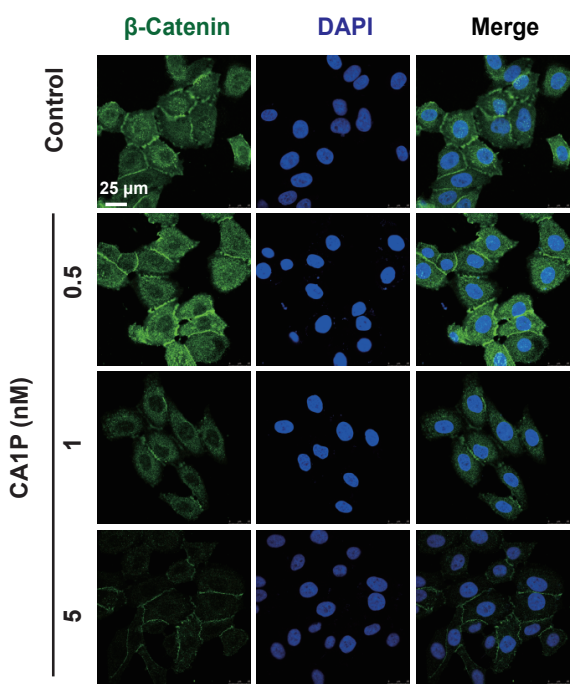
\begin{tabular}{lccccccccc} 
C CA1P (nM) & 0 & 1 & 5 & 10 & 0 & 1 & 5 & 10 \\
CHIR $99021(3 \mu \mathrm{M})$ & + & + & + & + & - & - & - & - \\
\hline
\end{tabular} Dynactin $\mathrm{p} 150$ p-AKT (S473) \begin{tabular}{llllllll}
1.0 & 1.0 & 0.8 & 0.8 & 0.9 & 0.9 & 0.8 & 0.8 \\
\hline & & & & & & &
\end{tabular}

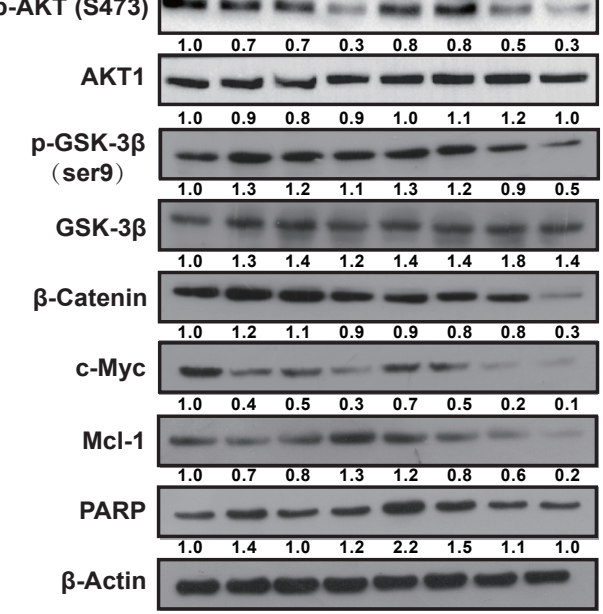
CHIR-99021 (3 $\mu \mathrm{M})$
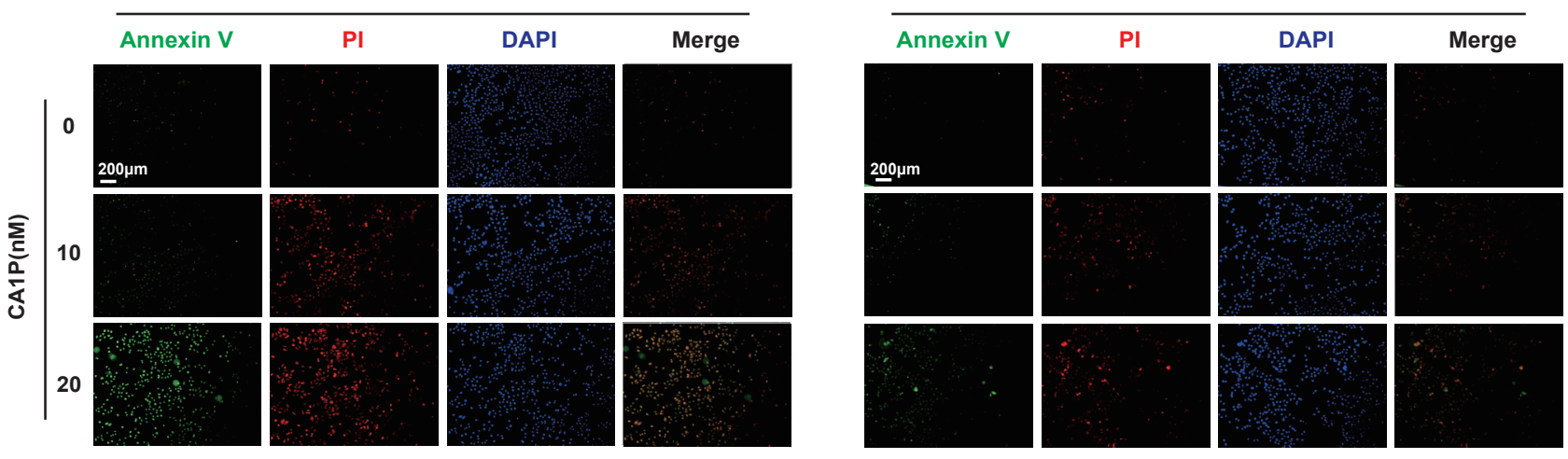
A

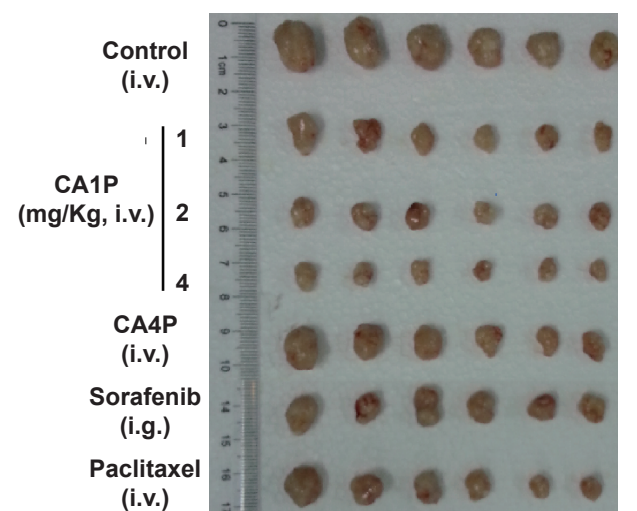

C

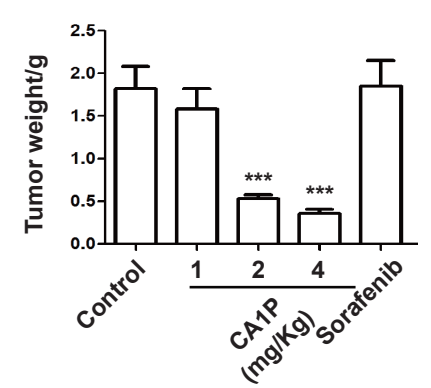

B

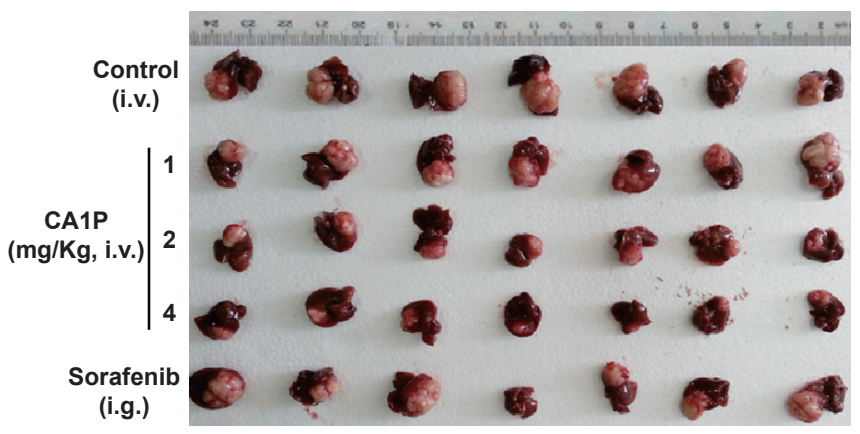

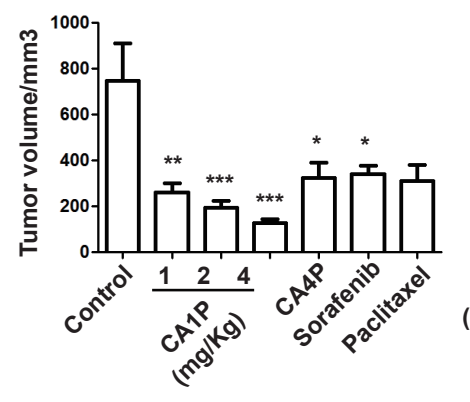
(mg/Kg, i.v.)

D

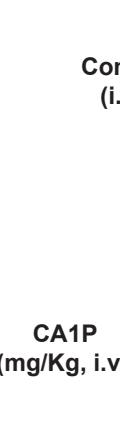

Control

(i.v.)

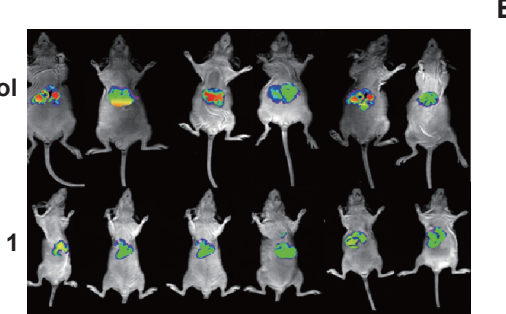

E
HepG2 tumor tissue protein

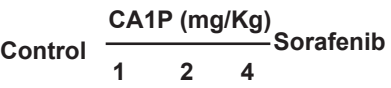

p-AKT (S473)

AKT1

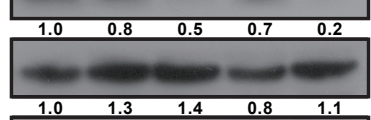

Wnt 3a

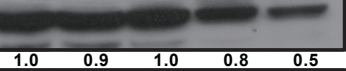

p-GSK $3 \beta$ (ser9)

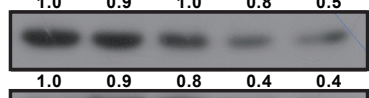

GSK $3 \beta$$$
\begin{array}{|lllll}
1.0 & 0.9 & 1.0 & 0.9 & 1.0 \\
\hline & & & &
\end{array}
$$

$\beta$-Catenin

c-Myc

Sorafenib (i.g.)
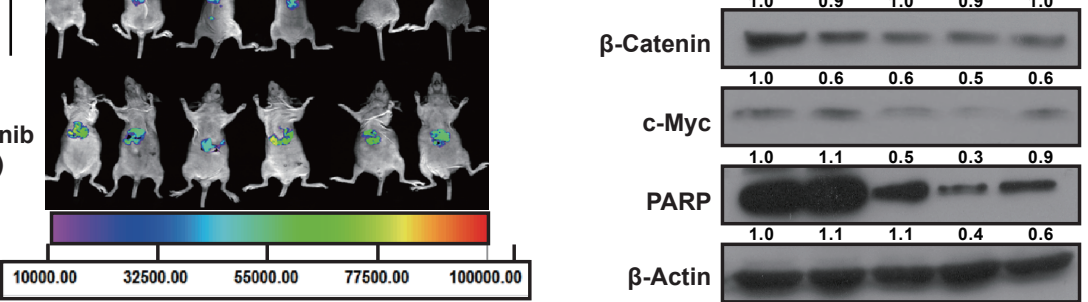
A

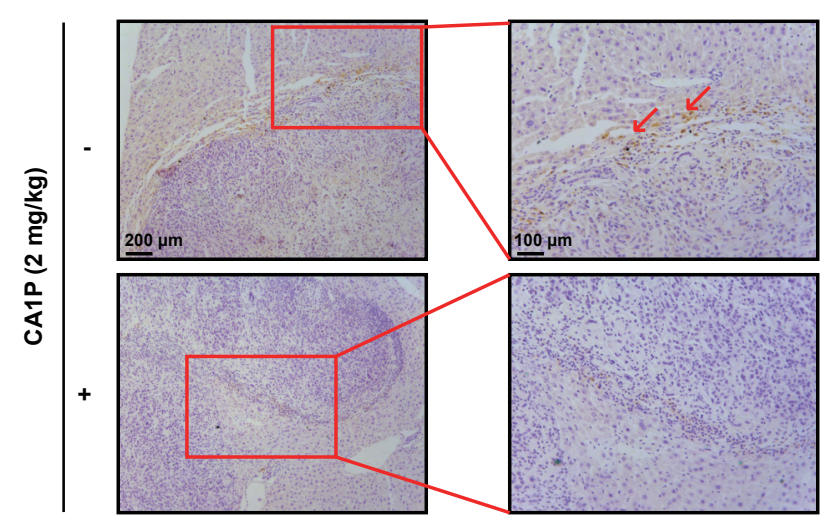

B

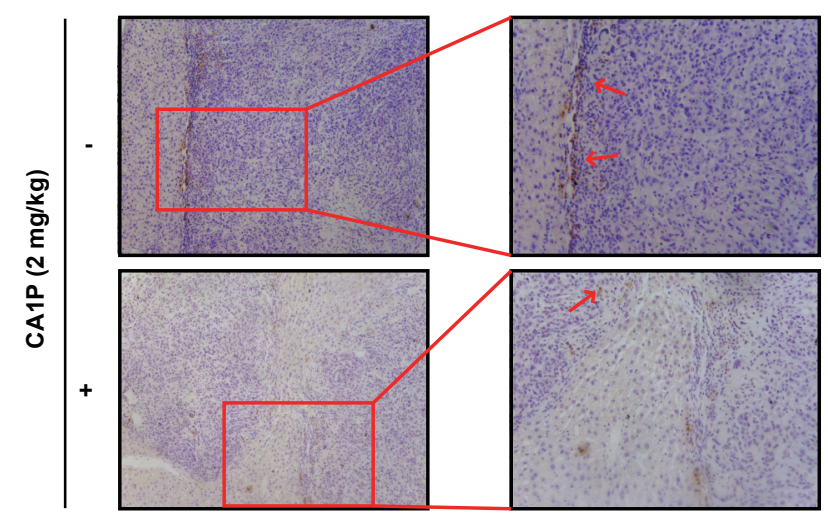

C

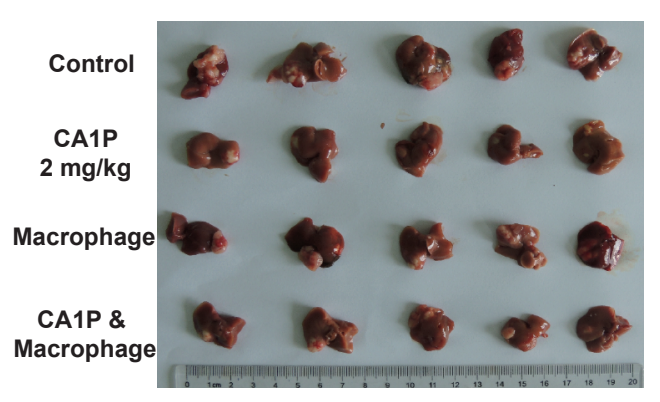

D

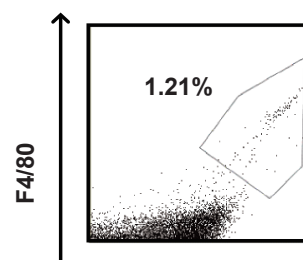

Control

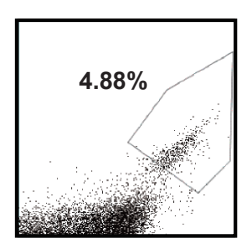

Macrophage

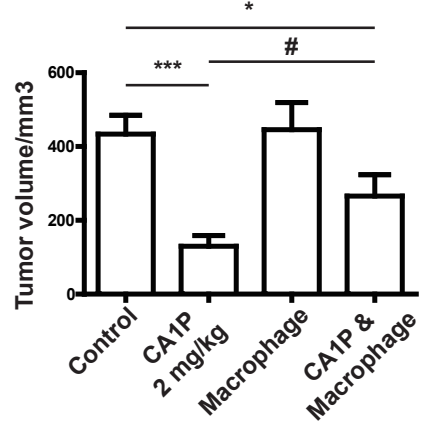

E
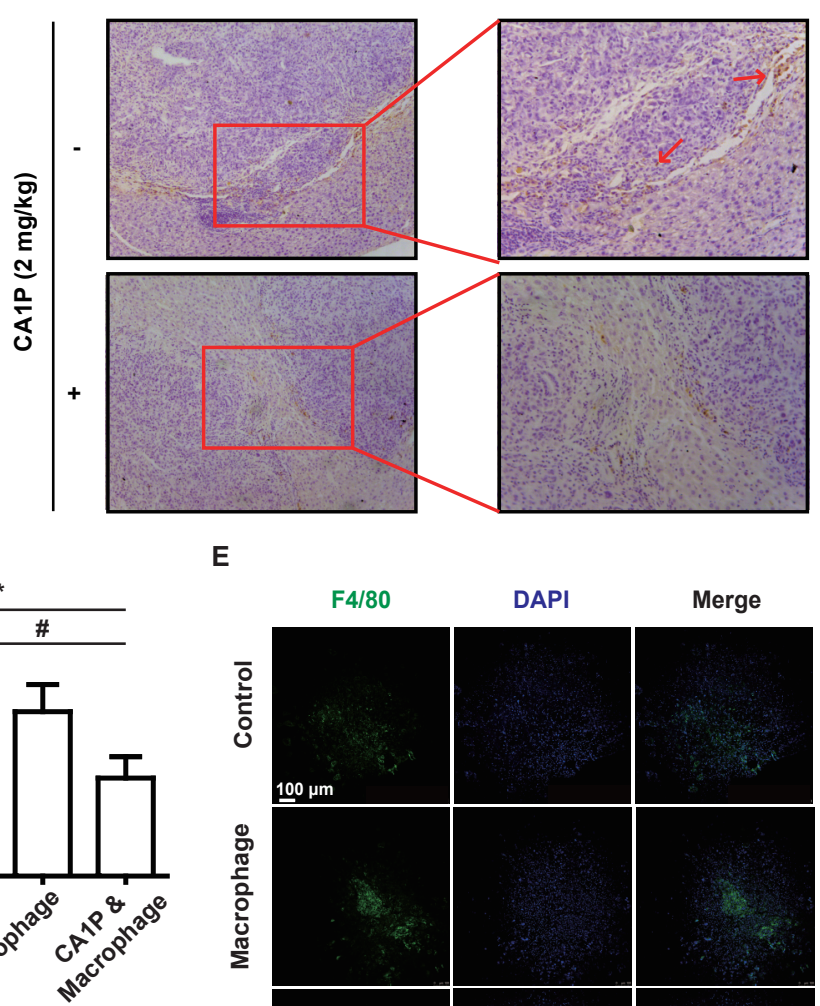

DAPI

Merge
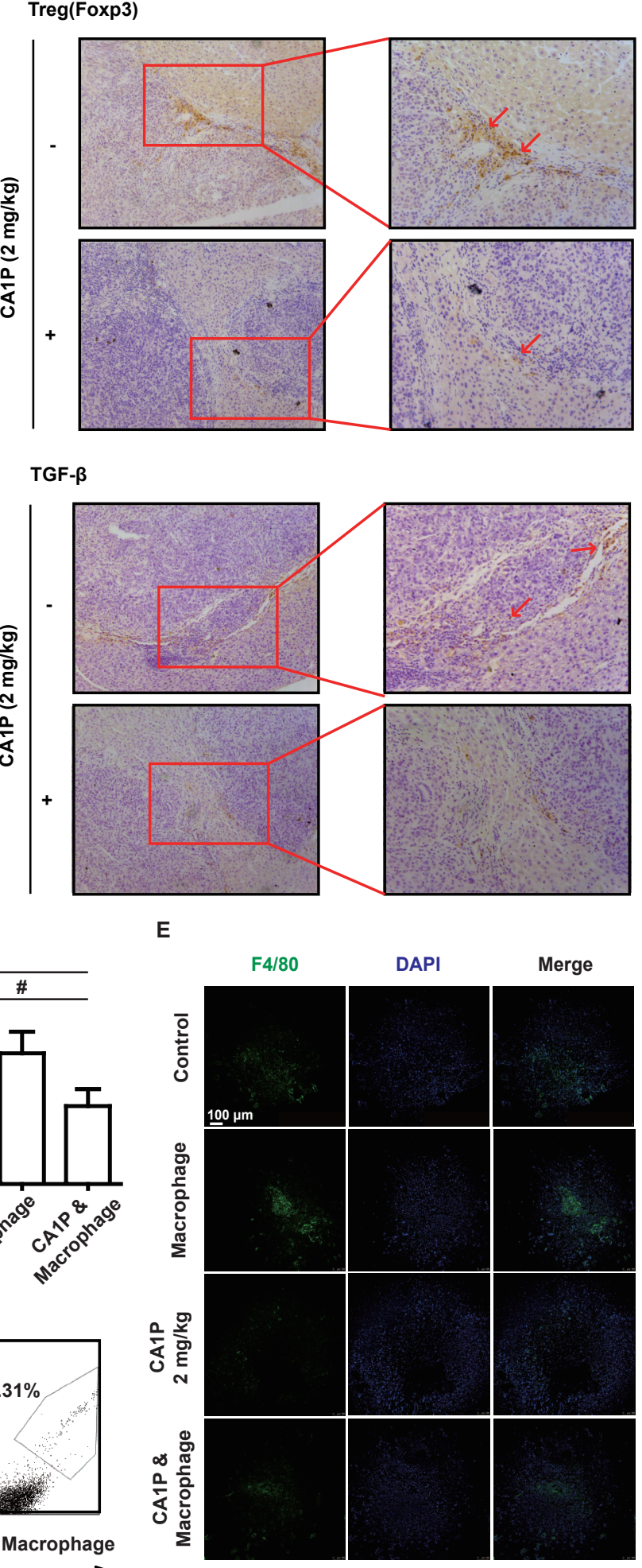

TGF- $\beta$

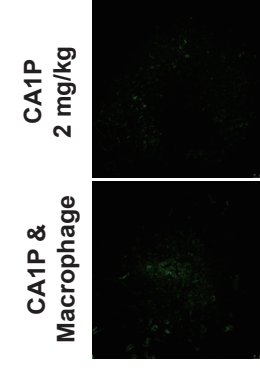

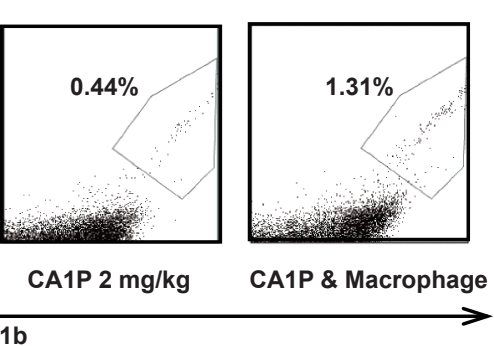


A
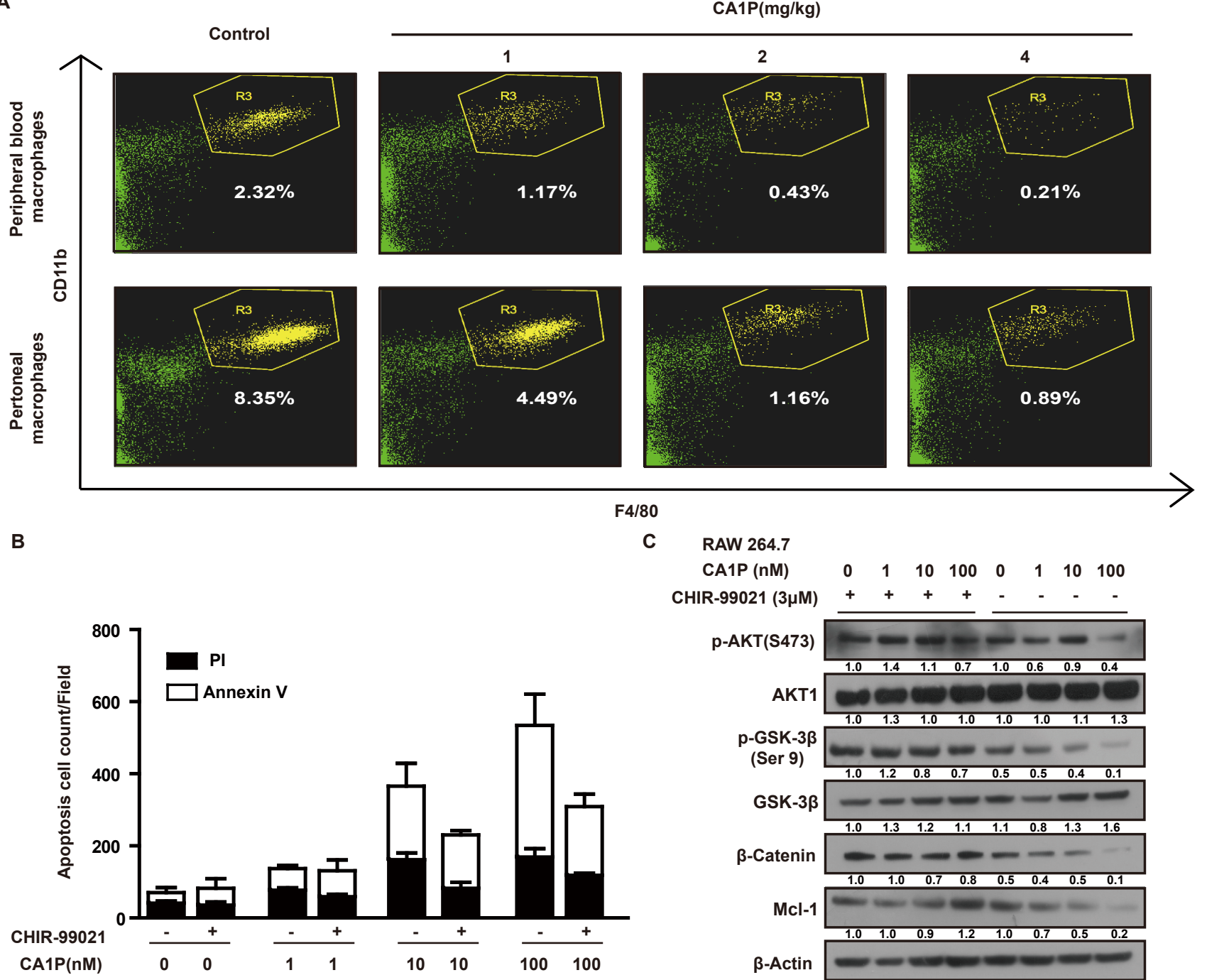
Hepatocarcinoma/Tumor-associated macrophages

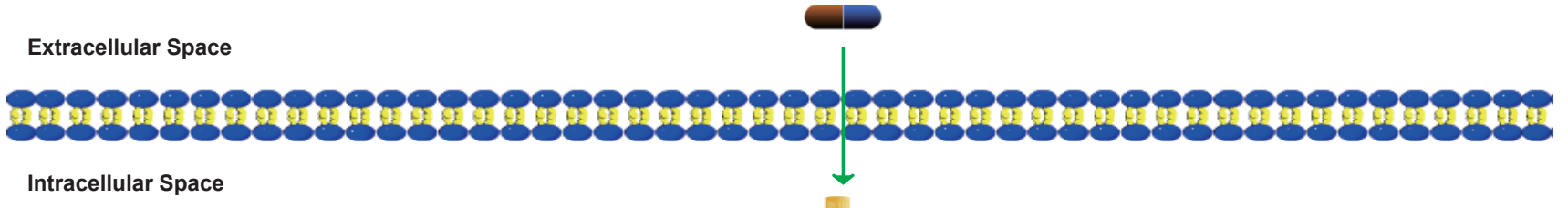

Intracellular Space

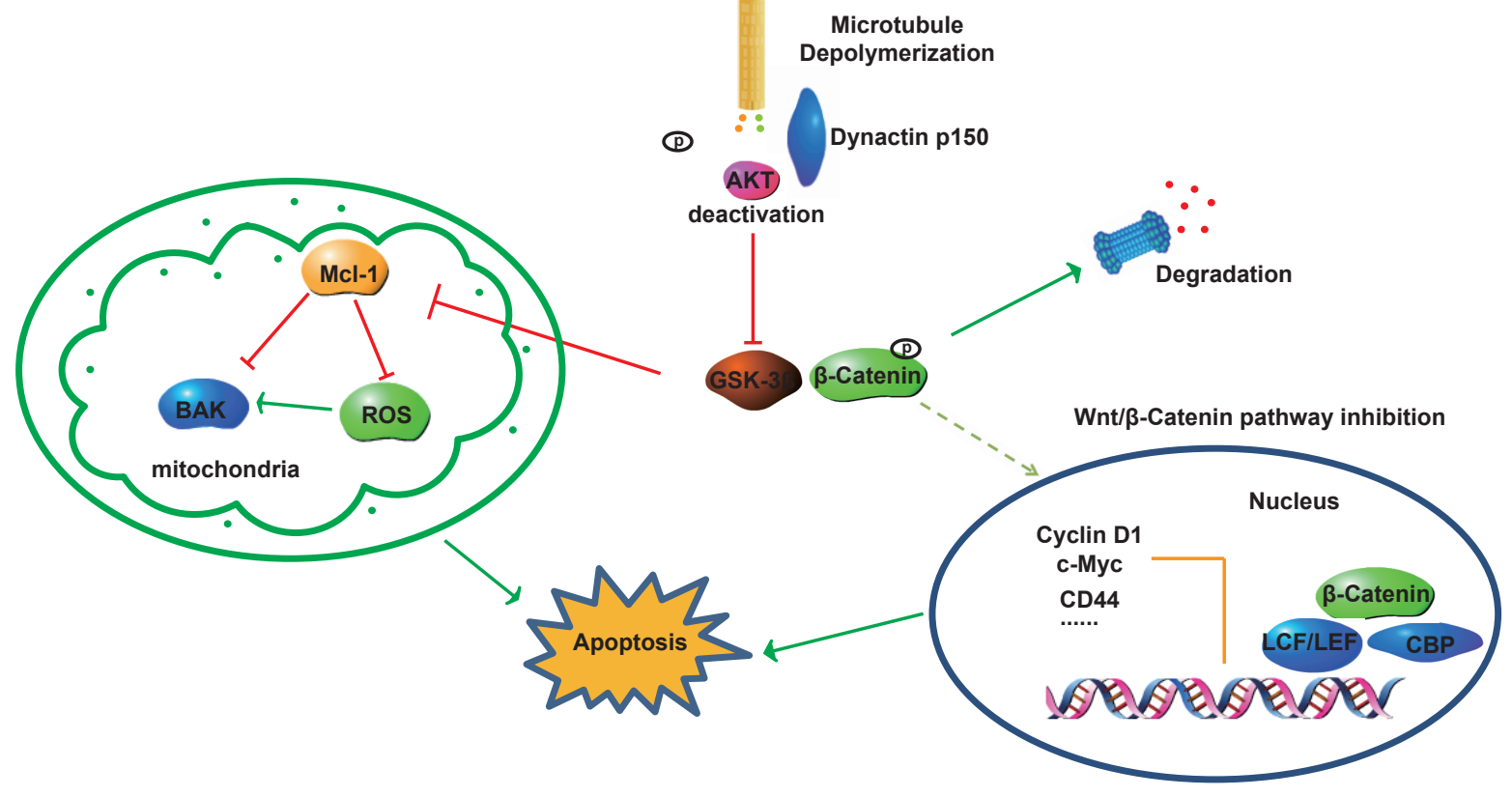


Table 1. IC50 value of CA1P on various tumor cell lines in vitro

\begin{tabular}{lclc}
\hline Tumor Cell Lines & IC50 $(\mathrm{nM})$ & Tumor Cell Lines & IC50 $(\mathrm{nM})$ \\
\hline HCC cell lines: & & Other Carcinoma cell lines: \\
\hline HepG2 & 9.2 & BGC-803 & 12.2 \\
SMMC-7721 & 12.8 & MDA-MB-231 & 17.6 \\
Hepa 1-6 & 32.9 & MCF-7 & 46.0 \\
LM-3 & 33.8 & A375 & 61.0 \\
Bel-7402 & 38.4 & NCI-1975 & 256.3 \\
Huh7 & 728.2 & CT-26 & 1075.0 \\
& & HT-29 & 2082.0 \\
& & A549 & 2247.0 \\
\hline
\end{tabular}

